\title{
APLICABILIDAD Y VALIDEZ DE LAS NORMAS DEL DERECHO INTERNACIONAL *
}

\author{
Jorge L. Rodríguez ** \\ Daniel E. Vicente ${ }^{* * *}$ \\ Universidad Nacional de Mar del Plata
}

RESUMEN. Las relaciones entre los sistemas jurídicos nacionales y el Derecho internacional y, en particular, la recepción de las normas internacionales de tutela de los derechos humanos en el Derecho interno, constituyen problemas teóricos muy complejos y de una muy significativa relevancia institucional. Recientemente se ha ofrecido una nueva interpretación de tales relaciones, que apela a la distinción entre validez y aplicabilidad de las normas jurídicas. En el presente trabajo se efectuará un examen crítico de dicha propuesta, a cuyo fin se introducirán inicialmente algunas consideraciones aclaratorias en torno al significado y alcance de las nociones de validez y aplicabilidad, luego de lo cual se intentarán mostrar algunas consecuencias problemáticas de la reconstrucción bajo análisis, para concluir con algunos apuntes en torno a una posible presentación alternativa.

Palabras clave: Derecho internacional, recepción de normas, validez, aplicabilidad.

ABSTRACT. The relations between national legal systems and international law and, more specifically, the reception of human rights international norms in national states, pose very complex theoretical difficulties of the utmost institutional relevance. In recent years a new interpretation of such relations has been offered, centered in the distinction between validity and applicability of legal norms. In this paper we offer a critical analysis of that proposal, introducing initially some preliminary remarks on the scope and meaning of the key notions of validity and applicability. On that basis we try to show some problematic consequences that follow from the interpretation examined and conclude with some observations in order to elaborate an alternative model of reconstruction.

Keywords: International law, reception of norms, validity, applicability.

* Fecha de recepción: 28 de octubre de 2008. Fecha de aceptación: 24 de noviembre de 2008.

** Doctor de la Universidad de Buenos Aires en el área de Filosofía del Derecho y profesor de Teoría General del Derecho de la Facultad de Derecho de la Universidad Nacional de Mar del Plata.

**** Doctorando y profesor de Teoría Constitucional y Derechos Humanos de la Facultad de Derecho de la Universidad Nacional de Mar del Plata. 


\section{INTRODUCCIÓN}

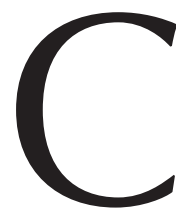

on posterioridad a la reforma de la Constitución argentina de 1994, las relaciones entre el Derecho nacional y el Derecho internacional y, en particular, la recepción de las normas internacionales de tutela de los derechos humanos en el Derecho interno y su repercusión sobre la supremacía constitucional, han sido problemas teóricos muy controvertidos. Una de las razones a las que ello obedece está dada por las dificultades interpretativas que ha suscitado el segundo párrafo del inciso 22 del art. 75 de la Constitución Nacional, el cual, luego de listar un conjunto de instrumentos internacionales de tutela de los derechos humanos, proclama: «...en las condiciones de su vigencia, tienen jerarquía constitucional, no derogan artículo alguno de la primera parte de esta Constitución y deben entenderse complementarios de los derechos y garantías por ella reconocidos...» ${ }^{1}$.

Mucho se ha escrito y discutido en la doctrina argentina desde entonces sobre estas cuestiones $^{2}$. Por su parte, la Corte Suprema de Justicia de la Nación no ha sido clara al examinar la cuestión, lo que se agrava debido a su particular forma de trabajo instrumentada a partir de 1990, que lleva a que en muchas decisiones de contenido constitucional trascendente no exista una clara mayoría de argumentos. Pasado el periodo de nueva integración del tribunal entre 1990 y 2005, la cuestión se ha reavivado como consecuencia de decisiones innovadoras en las que la Corte argentina ha otorgado un lugar de privilegio a las normas internacionales de tutela de los derechos humanos. Esto es, sin lugar a dudas, algo que en principio resulta merecedor del mayor de los elogios. Pero en algunos casos muy complejos la Corte ha adoptado posiciones cuyos alcances como precedentes son difíciles de predecir. A modo de ejemplo, considérese lo resuelto en Arancibia Clavel $^{3}$, Simón ${ }^{4}$, o Espósito ${ }^{5}$, todos relativos a hechos que habían significado violaciones a los derechos humanos, y también todos ellos relacionados con la extinción por prescripción de la acción penal. En los dos primeros la mayoría de la Corte estimó que si bien al tiempo en el que se produjeran los hechos bajo juzgamiento nuestro país no había ratificado la Convención sobre la Imprescriptibilidad de los Crímenes de Guerra $y$ de los Crímenes de Lesa Humanidad, debía considerarse que ya entonces era una norma vigente del Derecho internacional de origen consuetudinario el que los crímenes de lesa humanidad debían considerarse imprescriptibles, y de ello concluyó que también debía estimarse a dicho principio como vigente en nuestro país por ser parte integrante de la comunidad internacional. Se descartó así el argumento de que el principio de legalidad, consagrado en el art. 18 de la Constitución Nacional, que prohíbe entre otras cosas la aplicación de disposiciones penales posteriores al hecho que modifiquen in malam partem cualquier requisito del que dependa su punibilidad, pudiera obstar al carácter imprescriptible de la acción penal en el caso concreto, lo cual hizo decir a uno de los jueces que votara en disidencia en el primero de los casos mencionados que:

\footnotetext{
1 Un análisis preliminar de las dificultades del texto fue presentado en RODRíGUEZ y VICENTE, 1995.

2 Una temprana reseña de diversas posiciones al respecto puede consultarse en CASTORINA DE TARQUINI, 1995, y ABREgú y COURTIS, 1997.

3 CSJN, Fallos, 327:3294 (2004).

4 CSJN, Fallos, 327:5668 (2004).

5 CSJN, Fallos, 328:2056 (2005).
} 
«...El indiscutible carácter aberrante de los delitos imputados en esta causa "no puede servir de excusa para el apartamiento del orden jurídico vigente. Tanto o más interesa a éste la observancia de sus normas que la persecución de quienes han incurrido en hechos de aquel carácter"... La aplicación de los principios y normas del derecho de gentes... equivaldría a regirse por un Derecho natural, suprapositivo, constituido por criterios de justicia no previstos en el Derecho vigente al tiempo de los hechos cuyo juzgamiento se trata...» (voto del juez Belluscio, considerando 16).

En Espósito, por su parte, la Corte reconoció que en caso de quedar firme la resolución recurrida, la acción penal en el supuesto de hecho considerado se encontraría prescripta de conformidad con las normas de nuestro Derecho interno. No obstante, ordenó la prosecución de las actuaciones debido a que había existido un pronunciamiento internacional que condenaba a la Argentina por no haber adoptado los recaudos necesarios para instruir en un tiempo razonable la causa. La Corte interpretó así que no podía declararse prescripta la acción penal si ello podía implicar responsabilidad internacional del Estado argentino, sin perjuicio de que ello significara denegar al inculpado un Derecho no sólo reconocido por el Derecho interno sino, igualmente, por el Derecho internacional.

Como consecuencia de lo expuesto puede decirse que a la fecha no existe acuerdo ni en la doctrina ni en la jurisprudencia respecto de problemas interpretativos claves vinculados con la nueva configuración constitucional, entre ellos, a mero título ejemplificativo:

a) Si la relación de supremacía constitucional se ha visto afectada en Argentina por el hecho de dotar a un conjunto de instrumentos internacionales de tutela de los derechos humanos de la misma jerarquía que la Constitución Nacional o si, en cambio, lo preceptuado por el segundo párrafo del inciso 22 del art. 75 de la Constitución Nacional no ha modificado la primacía de la Constitución Nacional que parece seguirse de sus arts. 27 y 31 (vid. voto del juez Fayt en Simon y, anteriormente, del juez Belluscio en Arancibia Clavel o en Petric ${ }^{6}$.

b) Si los tratados internacionales a los que se atribuye jerarquía constitucional pueden generar conflictos normativos con otras cláusulas de la propia Constitución Nacional en su primera o segunda parte y, en su caso, quiénes están habilitados para resolver tales conflictos y cómo deben hacerlo (vid. el caso Felicetti ${ }^{7}$ respecto del art. 117 de la Constitución Nacional, o Simon respecto de los arts. 18 y 118 de la Constitución Nacional).

c) Si el legislador que pone en práctica la potestad de dotar de jerarquía constitucional a nuevos instrumentos internacionales ejerce competencia constituyente (reformadora del orden jerárquico establecido, al sumar una nueva norma a esa jerarquía condicionante) o meramente legislativa, pasible de control constitucional como en cualquier otro caso.

d) Si las condiciones de vigencia de los tratados con jerarquía constitucional incluyen o no las reservas y declaraciones interpretativas formuladas unilateralmente por los Estados parte al ratificarlos en sede internacional (vid. el caso Simon y el art. 15 del Pacto Internacional de Derechos Civiles y Políticos).

\footnotetext{
${ }^{6}$ CSJN, Fallos, 321:885 (1998).

7 CSJN, Fallos, 323:4130 (2001).
} 
e) Si corresponde interpretar esos tratados de conformidad con las pautas y métodos del Derecho internacional o según los propios del Derecho nacional; en particular, si la jurisprudencia internacional es de seguimiento obligatorio o más bien opera como guía en la interpretación y aplicación en el ámbito interno de las cláusulas de los tratados de derechos humanos (vid. casos Bramajo ${ }^{8}$, Giroldi ${ }^{9}$, Simon, etc.).

f) Si ha de dársele igual valor a los criterios (constantes y concordantes) de un órgano como la Comisión Interamericana en la solución de peticiones individuales y a los criterios de la Corte Interamericana en el mismo rol o en su rol consultivo (vid. casos Ekmekdjian ${ }^{10}$, Espósito, Simon, Arce ${ }^{11}$, etc.);

Recientemente se ha ofrecido una nueva interpretación del sistema de interrelación entre los Derechos nacionales y el Derecho internacional en materia de derechos humanos que, según se ha sostenido, permitiría ofrecer una nueva luz sobre aspectos polémicos como los reseñados. En diversos trabajos el profesor español J. L. REQUEJO PAGÉS apela a la distinción entre validez y aplicabilidad para reconstruir las relaciones entre las normas del Derecho internacional y los ordenamientos jurídicos nacionales ${ }^{12}$. En tal sentido, sostiene que las normas internacionales son aplicables en el Derecho interno pese a que el fundamento de su validez no se encuentra en la Constitución sino en el Derecho internacional.

REQUeJO PAGÉS considera que la aplicabilidad de cualquier norma presupone su validez, y que ordinariamente la norma que determina las condiciones de aplicación también establece los procedimientos para la generación de normas válidas. No obstante, la Constitución podría remitir a otras normas, las internacionales, sobre cuya validez no podría disponer, esto es, cuyo procedimiento de generación estaría regulado por el propio Derecho internacional. Pero siendo válidas de conformidad con tales estándares, ellas resultarían aplicables junto con las producidas a través de procedimientos internos previstos y regulados por la Constitución. En otras palabras, todas las normas aplicables serían válidas, pero su validez podría originarse por dos vías diferentes: a través de procedimientos normativos diseñados por la propia Constitución o a través de procedimientos regulados por normas independientes de las constitucionales. Con

$\begin{array}{ll}8 & \text { CSJN, Fallos, 319:1840 (1996). } \\ 9 & \text { CSJN, Fallos, 318:514 (1995). } \\ 10 & \text { CSJN, Fallos, 315:1492 (1992). } \\ 11 & \text { CSJN, Fallos, 320:2145 (1997). }\end{array}$

12 Cfr. Requejo Pagés, 1992, 1995 a y b y 1998, entre otros. La reconstrucción de REQUeJo PaGÉs parece receptada por el Tribunal Constitucional español en la DTC 1/2004, al sostenerse que no existiría contradicción entre la Constitución Española y el art. I-6 del Tratado de Roma de 2004, según el cual: «La Constitución y el Derecho adoptado por las instituciones de la Unión en el ejercicio de las competencias que se le atribuyen a ésta primarán sobre el Derecho de los Estados miembros». Para justificar esa conclusión, el Tribunal Constitucional entendió que: «...Primacía y supremacía son categorías que se desenvuelven en órdenes diferenciados. Aquélla, en el de la aplicación de normas válidas; ésta, en el de los procedimientos de normación. La supremacía se sustenta en el carácter jerárquico superior de una norma y, por ello, es fuente de validez de las que le están infraordenadas, con la consecuencia, pues, de la invalidez de éstas si contravienen lo dispuesto imperativamente en aquélla. La primacía, en cambio, no se sustenta necesariamente en la jerarquía, sino en la distinción entre ámbitos de aplicación de diferentes normas, en principio válidas, de las cuales, sin embargo, una o unas de ellas tienen capacidad de desplazar a otras en virtud de su aplicación preferente o prevalente debida a diferentes razones. Toda supremacía implica, en principio, primacía..., salvo que la misma norma suprema haya previsto, en algún ámbito, su propio desplazamiento o inaplicación. La supremacía de la Constitución es, pues, compatible con regímenes de aplicación que otorguen preferencia aplicativa a normas de otro Ordenamiento diferente del nacional siempre que la propia Constitución lo haya así dispuesto...». 
tales remisiones, la Constitución derivaría a otro sistema normativo la determinación de los presupuestos de validez de las normas que eventualmente habrían de integrarse en el ordenamiento interno. Estas normas así integradas serían normas que pertenecen al ordenamiento que las recepta. El Derecho internacional sería, en cierto sentido, un ordenamiento incompleto, puesto que si bien estaría capacitado para producir normas válidas, sólo los ordenamientos nacionales podrían dotar a tales normas de la aplicabilidad imprescindible para hacerlas efectivas.

De conformidad con este punto de vista, un ordenamiento jurídico nacional, presidido por la Constitución, se descompondría en dos subsistemas normativos, uno de los cuales (el subsistema nacional) dependería de aquélla para producir normas válidas, y otro (el subsistema internacional) que sólo recibiría de la Constitución su aplicabilidad, cualidad que por cierto también tendrían las normas internas.

Una consecuencia de esta reconstrucción consistiría en que la Constitución sólo sería suprema respecto de las normas internacionales en tanto la primera determinaría la condición de normas aplicables de las segundas. Si la Constitución no constituye el fundamento de validez de las normas internacionales, pero sí es condición de su aplicabilidad, y si ésta se verifica aún en el supuesto de contradicción entre una norma internacional y otra incluida formalmente en la Constitución, cabría concluir que un posible conflicto entre la Constitución y una norma internacional debería resolverse interpretando que la norma constitucional que incorpora a la internacional al ordenamiento es una norma de reforma de la Constitución. Por otra parte, de este planteo se derivaría que los conflictos entre una norma del Derecho internacional y una ley han de resolverse por dos caminos diferentes: si la ley fuese anterior, se apelaría a la validez, poniéndose en un mismo plano a la ley anterior y al acto de aprobación del tratado, y la ley anterior sería inválida por aplicación del principio de lex posterior. En cambio, si la ley fuese posterior, se apelaría a la aplicabilidad y no a la validez, de modo que, pese a ser ambas válidas, la internacional gozaría de aplicabilidad en los términos fijados por su sistema de origen, que resultaría preferente, apoyando tal conclusión en una particular interpretación del art. 27 de la Convención de Viena sobre Derecho de los Tratados. Requejo Pagés sostiene además que los tratados no forman parte del «bloque de constitucionalidad» —en el sentido español de tal expresión- ${ }^{13}$ pues no pueden condicionar la validez de las normas del Derecho interno y tampoco pueden ser interpretados por el Tribunal Constitucional sino por los órganos de aplicación de sede internacional.

En Argentina A. GIL DomíngueZ, también en diversos trabajos ${ }^{14}$, ha seguido esta línea de pensamiento. A su juicio, el concepto de validez permitiría establecer en forma completa el fundamento de un sistema de normas que pueda reconducir su existencia a una norma positiva superior. Una norma sería válida o inválida siempre que se adecue a las potestades de producción jurídica establecidas en una norma superior. No obstante, se presentaría una dificultad cuando «confluyen diversos sistemas normati-

13 Bajo esta interpretación, el bloque de constitucionalidad consistiría en el conjunto de disposiciones normativas que permiten completar el reparto de competencias entre el Estado Nacional y las Comunidades Autónomas, en atención al particular y complejo modelo de Estado que diseñara el constituyente español de 1978 ( $c f r$. FAVOREAU y RuBio LlORENTE, 1991, p. 98).

${ }^{14}$ Cfr. Gil Domínguez, 2004 y 2007, entre otros. 
vos derivados de normas primarias distintas». En este supuesto, la validez resultaría insuficiente como elemento integrador de normas que pertenecen a sistemas jurídicos con existencia independiente. La validez permitiría determinar el conjunto de normas que integran el sistema, pero no sería posible «inferir la validez de las normas de un sistema distinto», que tendría sus propios criterios de validez, y ello porque el concepto de validez sería «autorreferencial» en el sentido de que sólo operaría en el interior de cierto sistema.

Una manera de articular sistemas jurídicos concurrentes en la administración del ejercicio de la fuerza en un mismo ámbito territorial, temporal y personal, consistiría en recurrir a la categoría de la aplicabilidad, entendida como una condición en virtud de la cual una norma «forma parte de un ordenamiento sin depender en su validez de la norma de articulación de los sistemas normativos concurrentes». En supuestos semejantes el constituyente partiría de la validez presupuesta e indisponible de tales normas, y se arribaría a un ordenamiento que sería el resultado de la conjugación de una pluralidad de sistemas normativos conducidos a la unidad e integración mediante una Constitución, que cumpliría el rol de una norma sobre la aplicación de normas. $\mathrm{La}$ «regla de reconocimiento constitucional» funcionaría como fuente de validez de sus propias normas y, a la vez, «visualiza las normas del sistema externo, su régimen vigente (establecido por órganos propios de producción y validación) y oportunamente las aplica con el objeto de determinar su ámbito de actuación o bien para validar o invalidar normas secundarias» ${ }^{15}$.

15 GIL DomínguEZ utiliza la expresión «regla de reconocimiento constitucional» para referirse a su concepción de la pauta que ha de emplearse para evaluar la validez de las normas inferiores de un sistema jurídico nacional, que opone a las nociones de supremacía constitucional y de bloque de constitucionalidad. Esta «regla de reconocimiento constitucional» combinaría una fuente interna (el texto constitucional) y una fuente externa (el Derecho internacional) para determinar el parámetro de verificación de la validez de las restantes normas del sistema. Si bien la expresión evoca la noción hartiana de regla de reconocimiento (cfr. HART, 1961 y 1994), no resulta fácil congeniar lo que afirma GIL DOMínGUEZ con el núcleo del pensamiento de HART. En la teoría de HART, la regla de reconocimiento es una regla social, pero no es una regla en el mismo sentido en el que lo son las reglas primarias del sistema, dado que ella no establece derechos u obligaciones respecto de los ciudadanos. Podría en todo caso discutirse si impone o no deberes sobre los jueces (vid., al respecto, la interesante polémica sostenida por BULYGIN (1991) y RUIZ MANERO (1991) en torno al estatus meramente conceptual o prescriptivo de la regla de reconocimiento), pero lo cierto es que el uso de la expresión en HaRT se justifica por el hecho de que se trata de aquella regla secundaria que reúne el conjunto de los criterios compartidos al menos por los órganos jurisdiccionales para identificar las normas que conforman cierto sistema jurídico. Por ello, el calificativo de «constitucional» que agrega GIL DomíNGUEZ resulta extraño como predicado de la regla de reconocimiento: si esta última ha de permitir identificar todas las reglas que conforman un sistema jurídico, también debe poder identificar a la constitución como parte del sistema, de modo que no puede hacerse colapsar a la regla de reconocimiento en la constitución. Por cierto, es corriente que ciertas normas constitucionales expresen parcialmente criterios de identificación de otras normas de un sistema jurídico. Así podría interpretarse el art. 31 de la Constitución Nacional, al sostener que: «Esta Constitución, las leyes de la Nación que en su consecuencia se dicten por el Congreso y los tratados con las potencias extranjeras son la ley suprema de la Nación...». Pero, como parece obvio, esta sintética enumeración no es la regla de reconocimiento del Derecho argentino: no sólo porque hay una infinidad de normas del Derecho argentino que no están allí comprendidas, sino porque, como se dijo, la regla de reconocimiento del Derecho argentino sería, según la propuesta de HART, una muy compleja regla, que podría reconstruirse a partir de la práctica de los tribunales, y que debería poder identificar entre otras cosas a la Constitución Nacional como miembro del Derecho argentino. En realidad, parecería que el uso que hace GIL DomíNGUEZ de la expresión «regla de reconocimiento constitucional» obedece exclusivamente al hecho de que, en su opinión, nuestra Constitución validaría las normas internas creadas a través de procedimientos por ella establecidos pero, a la vez, «...reconoce las condiciones de validez de la fuente externa y mediante la aplicabilidad combina dicho producto normativo con la fuente interna, estableciendo el parámetro de verificación de la validez de las normas inferiores» (GIL DOMínGUEZ, 2007, p. 14). Siendo ello 
La posición reseñada posee una virtud capital que consiste en la propuesta de distinguir dos nociones que, pese a los esfuerzos que en tal sentido ha efectuado la teoría general del Derecho, en general se confunden: la validez y la aplicabilidad de las normas. Sobre esa base se intentan reconstruir las relaciones entre los Derechos nacionales y el Derecho internacional, superando las limitaciones que ofrecerían las posturas tradicionales al respecto. Además, ella permitiría justificar una respuesta a dificultades interpretativas como las que sintéticamente enunciáramos, por ejemplo, que la potestad para controlar la compatibilidad entre los tratados de cualquier tipo y la constitución no podría ser ejercitada por los jueces nacionales por no tratarse de una cuestión de validez o, en todo caso, que ella no debería efectuarse tomando en cuenta la relación de supremacía constitucional sino sobre la base de otros criterios, como el de la aplicabilidad preferente de las normas del Derecho internacional, o que los tratados de derechos humanos no podrían sino ser interpretados de conformidad con las pautas, los métodos y de conformidad con las opiniones de los órganos del Derecho internacional, cualquiera sea su carácter, puesto que ellos serían aplicables en el ámbito interno sin que sus condiciones de validez puedan ser revisadas en dicha sede.

Hay, no obstante, algunos puntos de esta propuesta que merecen ser repensados. En lo que sigue introduciremos en primer lugar algunas consideraciones aclaratorias en torno al significado de las dos expresiones que ocupan un papel central en este análisis: las nociones de «validez» y «aplicabilidad» de las normas jurídicas. Luego de este recorrido preliminar intentaremos mostrar algunas consecuencias problemáticas del punto de vista que asumen ReQuejo Pagés y Gil DomíngueZ, para concluir con algunos apuntes en torno a una posible reconstrucción alternativa.

\section{AMBIGÜEDAD DE LA EXPRESIÓN «VALIDEZ»}

Pese a que la validez jurídica es una de las nociones centrales de la teoría del Derecho, y a que la mayoría de los iusfilósofos han intentado suministrar una reconstrucción satisfactoria de este concepto, subsisten hoy día serias dificultades para precisar su alcance. Además, esas dificultades han dado lugar a la postulación de construcciones teóricas como la famosa pero inaceptable norma fundante básica kelseniana, o la más atractiva pero no menos problemática regla de reconocimiento hartiana.

Una de las contribuciones más significativas para esclarecer los diferentes sentidos de la expresión «validez jurídica» ha sido ofrecida por E. BULYGIN en diversos trabajos, algunos de los cuales han devenido clásicos sobre el punto ${ }^{16}$. En trabajos más recientes BULYGIN ha reexaminado el problema, vinculándolo con las discusiones contemporáneas sobre la normatividad del Derecho ${ }^{17}$. Si bien su análisis es en lo fundamental impecable, hay algunas cuestiones en las que estimamos necesario introducir algunas precisiones.

así, la expresión «regla de reconocimiento constitucional» sería empleada para hacer referencia a cierto modo de interpretar la configuración (contingente por cierto) que asume nuestro sistema jurídico para determinar la validez de algunas de sus normas y, como tal, no podría identificarse — salvo en lo nominal— con la teoría de HART.

16 Especialmente, BuLYGin, 1990.

17 Cfr. Bulygin, 2004 y 2006. 
Recuérdese que para KELSEN la validez de una norma depende de haber sido creada de conformidad con lo que disponen normas de jerarquía superior, fundamentalmente en lo que hace al órgano competente para su promulgación y al procedimiento que ha de seguirse para hacerlo. Sin embargo, KELSEN no define «validez» de este modo. Si bien muchos identifican la validez de una norma con su creación regular de conformidad con lo que otra dispone, en la Teoría Pura ese no es más que un criterio para determinar cuándo una norma es válida, no una definición de «validez». La validez es definida por KELSEN, alternativamente, como la «existencia específica» de una norma o como la «fuerza obligatoria de una norma» ${ }^{18}$.

BulYGIN destaca que KELSEN confunde dos diferentes nociones de validez, una de ellas descriptiva y la otra prescriptiva ${ }^{19}$. En sentido descriptivo, decir que una norma jurídica es válida significa que ella pertenece a un determinado sistema jurídico - lo que se correspondería con la noción kelseniana de «existencia específica»-. En sentido prescriptivo, decir que una norma jurídica es válida significa que es obligatorio hacer lo que ella prescribe - lo que se correspondería con la noción kelseniana de «fuerza obligatoria»-. Para Bulygin, la noción descriptiva de validez como pertenencia a un sistema es relativa, pues una norma puede pertenecer a un sistema jurídico y no pertenecer a otro. En cambio, la noción prescriptiva de validez como fuerza obligatoria sería absoluta, pues no aludiría a una relación con otras normas sino a un atributo.

KELSEN asocia de manera indebida estas dos nociones bajo el supuesto de que ellas resultan equivalentes: todas y sólo aquellas normas que pertenecen a cierto sistema jurídico tendrían, desde su punto de vista, fuerza obligatoria. Sin embargo, una vez que se distinguen los dos sentidos apuntados, como parece sensato hacer, una compleja cuestión que se presenta en la teoría kelseniana, esto es, la del fundamento último de la validez de las normas de un sistema jurídico, puede disolverse como un pseudoproblema, y la desconcertante respuesta que KELSEN ofrece a esa dificultad, esto es, la teoría de la norma fundante básica, puede descartarse como un intento, fallido por cierto, de resolver dos problemas diferentes a través de una respuesta única.

Siguiendo el análisis de BuLYGIN, en sentido descriptivo una norma jurídica es válida si pertenece a cierto sistema jurídico. La membresía al sistema de ciertas normas habitualmente depende de su relación con otras normas. Así, por ejemplo, un criterio común de pertenencia de una norma $\mathrm{N} 1$ a un sistema jurídico consiste en que ella haya sido creada por cierta autoridad A1, y que exista otra norma N2 en el sistema que confiera a A1 la potestad jurídica de crear N1. Por supuesto, este criterio, así como cualquier otro que haga depender la pertenencia de cierta norma a un sistema de su relación con otras normas, presupone la preexistencia en el sistema de al menos una norma, pues de lo contrario ninguna norma pertenecería a él. En otras palabras, todo sistema jurídico estará integrado por ciertas normas derivadas o dependientes -aquellas cuya pertenencia al sistema depende de su relación con otras normas del sistema- y al menos una norma no derivada o independiente - aquella cuya pertenencia al

18 Cfr. KELSEN, 1945, pp. 115-116, y 1960, p. 193.

19 El uso ambiguo de la noción de validez en la Teoría Pura también ha sido destacado, entre otros, por Ross (1961), RAZ (1979a y b), NinO (1985) y GARZÓN VALDÉS (1993). Para un examen crítico de las tesis kelsenianas relativas a las relaciones entre el Derecho internacional y los Derechos nacionales, vid. HART, 1968. 
sistema no depende de su relación con otras normas del sistema- ${ }^{20}$. En consecuencia, si bien es posible justificar la pertenencia a un sistema jurídico de cualquier norma derivada a través de una serie de pasos en una cadena de validez en este sentido, cuando se llega a la primera norma positiva del sistema (la primera constitución histórica o constitución originaria en la teoría kelseniana), la pregunta acerca del fundamento de su validez como pertenencia al sistema carece de sentido, porque sería tanto como preguntar de dónde se deriva una norma no derivada. En consecuencia, BULYGIN afirma que la constitución originaria de un sistema jurídico es la que lo define como tal $\mathrm{y}$, consiguientemente, no se requiere de ninguna justificación para su pertenencia al sistema, de modo que en este sentido de validez, la idea de una norma fundante presupuesta como herramienta teórica para justificar la validez de la constitución originaria resultaría innecesaria.

A diferencia del supuesto anterior, de acuerdo con el sentido prescriptivo de validez, una norma jurídica es válida si es obligatorio hacer lo que ella dispone. En su análisis originario de la Teoría Pura del Derecho, BuLYGIN sostenía que KELSEN estaba en lo cierto al considerar que el fundamento de la validez como fuerza obligatoria de una norma jurídica sólo puede consistir en la validez como fuerza obligatoria de otra norma. Si la norma N1 fue creada por una autoridad A1, cuya potestad jurídica para hacerlo fue conferida por otra norma N2, entonces N2 estaría prescribiendo el deber de cumplir con N1. Esto implicaría, según BuLYGin, que si la validez como fuerza obligatoria de una norma es relativa a la validez como fuerza obligatoria de otra norma, la cadena de validez necesaria para justificar la validez de cualquier norma en este sentido debería ser infinita, a menos que se acepte que ciertas normas son válidas de manera autoevidente o absoluta. Semejante papel no podría cumplirlo la constitución originaria de un cierto sistema jurídico, porque tendría perfecto sentido preguntarse por la fuerza obligatoria de esa primera norma positiva. En consecuencia, KELSEN habría introducido su idea de una norma fundante básica como herramienta teórica para conferir potestad jurídica al primer legislador. Sin embargo, la norma fundante no sería una norma válida: su validez debería ser presupuesta. Por ello, BULYGIN sostiene que la validez como fuerza obligatoria de las normas de un sistema jurídico no puede derivar de una norma básica presupuesta, sino que requeriría de un fundamento más fuerte: un juicio moral objetivo que establezca que se debe hacer lo que ese sistema dispone, el cual no podría tener cabida en la Teoría Pura de KeLSEN. La conclusión de BULYGIN es que de acuerdo con el concepto de validez como fuerza obligatoria, la idea de una norma fundante presupuesta no resulta suficiente para justificar la validez de la constitución originaria y que, en última instancia, la noción prescriptiva de validez sería incompatible con el positivismo jurídico.

En sus contribuciones más recientes sobre el punto BULYGIN da algunos pasos adicionales en esta línea de pensamiento. Siguiendo a A. Ross ${ }^{21}$, sostiene que la validez jurídica como fuerza obligatoria carecería de significado a menos que se la interprete como una referencia al deber moral de obedecer el Derecho. Ello porque si la validez como fuerza obligatoria de cierta norma N1 se interpreta como un deber jurídico impuesto por otra norma $\mathrm{N} 2$ de cumplir con N1, se trataría de un concepto vacío porque

\footnotetext{
${ }^{20}$ Cfr. CaRaCciolo, 1988, p. 31.

${ }^{21}$ Cfr. Ross, 1961.
} 
el deber impuesto por N2 no prescribiría ninguna conducta que no esté ya ordenada por la propia norma N1. De manera que el único modo de tornar inteligible la idea de la validez como fuerza obligatoria consistiría en interpretarla como un deber no jurídico sino moral, y ello no podría congeniarse con el programa positivista de KELSEN. Sobre la base de estas consideraciones críticas, BULYGIN piensa que la noción de validez como fuerza obligatoria debería ser reemplazada por un concepto prescriptivo diferente: el concepto de aplicabilidad, esto es, el deber de aplicar una norma jurídica impuesto por otra norma jurídica ${ }^{22}$. Afirma que ciertas normas de un sistema jurídico imponen sobre los jueces el deber jurídico de aplicar otras normas a ciertos casos, y esas normas no resultarían superfluas porque lo que ellas prescriben (aplicar una norma a un caso) no coincidiría con las obligaciones impuestas por las normas aplicables. Por otra parte, a diferencia de la validez como fuerza obligatoria, a cuyo respecto una noción relativa presupondría una absoluta, el concepto de aplicabilidad sería autosuficiente, pues sería relativo a la existencia de otra norma, no a su aplicabilidad. La justificación de la aplicabilidad de cierta norma podría requerir remontarse a toda una cadena de normas, pero esa cadena concluiría necesariamente en una norma que no sería ni aplicable ni inaplicable ${ }^{23}$.

A nuestro criterio, BULYGIN está en lo cierto cuando afirma que KELSEN confunde una noción descriptiva y una prescriptiva de validez, y su idea de que la inadmisible teoría de la norma fundante es una consecuencia derivada de esa ambigüedad está fuera de toda discusión. Sin embargo, la conclusión de BULYGIN de que sólo la noción de validez como pertenencia a un sistema sería compatible con la tesis central del positi-

22 El concepto de aplicabilidad es examinado cuidadosamente en BulYgin, 1982.

23 Si una norma N2 se limitara a prescribir el deber de hacer aquello que otra norma N1 concretamente determinada establece, parece correcto sostener, tal como lo hacen Ross y BULYGIN, que N2 resultaría superflua, porque no prescribiría ninguna acción que no se encuentre ya ordenada por la propia N1. Pero la existencia de N2 tendría perfecto sentido si impusiera el deber jurídico de obedecer todas las normas que posean cierta propiedad, por ejemplo, todas aquellas que hayan sido dictadas por cierta autoridad A1, siendo N1 una de tales normas. Considérese el caso de una pareja que debe salir una noche e instruye a su hijo pequeño: «Haz todo lo que la niñera te ordene». Podría decirse que esta es una norma incompleta, porque para individualizar qué se debe hacer para cumplirla habrá que esperar a que la niñera indique algún curso de acción, pero no que resulta superflua. El dictado de normas que establecen el deber de cumplir con otras normas parece perfectamente sensato cuando existen normas de distintos estratos jerárquicos, como así también cuando es preciso ofrecer una guía acerca de qué norma debe seguirse si existen varias en conflicto. Como se indica en el texto, BulYGin propone sustituir el concepto de validez como fuerza obligatoria, al que reputa incompatible con una teoría positivista del Derecho, por el concepto de aplicabilidad, esto es, el deber impuesto sobre los jueces por una norma jurídica de aplicar otra norma a un caso. No obstante, los jueces se definen como funcionarios encargados de solucionar ciertos casos por aplicación de normas jurídicas generales, de manera que constituye un deber funcional para los jueces el de emplear normas jurídicas como fundamento de sus decisiones. Ese deber genérico puede registrar excepciones, pero al menos prima facie los jueces deben aplicar a los casos que han de resolver las normas jurídicas que los regulan. Por consiguiente, una norma jurídica que se limitara a imponer sobre los jueces el deber de aplicar cierta otra norma concretamente individualizada a un caso por ella regulado parece tan superfluo como dictar una norma N2 que imponga el deber de cumplir con otra norma N1 concretamente individualizada. Si la noción de aplicabilidad ha de ser admitida como significativa es porque tiene perfecto sentido promulgar una norma que imponga sobre los jueces el deber de aplicar a cierta clase de casos aquellas normas que posean cierta característica (por ejemplo, la norma que obliga a los jueces a aplicar en los casos penales aquellas normas que resulten más benignas para el acusado). Ello es muy frecuente como una forma de establecer un criterio para seleccionar alguna de entre varias normas potencialmente en conflicto. Pero entonces, sobre la base de un argumento semejante, la idea de una norma que imponga el deber de cumplir con otras normas debería igualmente admitirse como significativa. 
vismo, mientras que la noción de validez como fuerza obligatoria debería ser rechazada desde tal perspectiva, parece un tanto desconcertante.

El positivismo jurídico, entendido como una determinada manera de caracterizar el Derecho, sostiene que no existe una conexión necesaria entre el Derecho y la moral porque la identificación de una norma como miembro de un sistema jurídico dependería exclusivamente de ciertos hechos sociales complejos y no de una evaluación moral de su contenido. En consecuencia, el positivismo jurídico está obligado a diferenciar de manera tajante la identificación de una norma como jurídica del deber de obedecerla o aplicarla. En palabras de HART, decir que cierta norma es parte de un sistema jurídico no suministra una respuesta concluyente a la cuestión de si existe un deber moral de obedecerla ${ }^{24}$.

Siendo ello así, una vez que se distinguen los sentidos prescriptivo y descriptivo de validez — tal como BulYGIN los caracteriza-, ¿por qué razón una teoría positivista del Derecho debería rechazar la noción prescriptiva como incompatible con su tesis central? En la medida en que el problema de la identificación de las normas jurídicas y el problema de su fuerza moral se consideren independientes, no parece existir ninguna posible contradicción entre la tesis de la separación conceptual entre el Derecho y la moral y la aceptación de la noción de validez como fuerza obligatoria ${ }^{25}$.

${ }^{24}$ Cfr. HART, 1961, pp. 259-260.

25 BuLYGin a veces afirma que la validez prescriptiva es una noción absoluta, pues no se referiría a una relación sino a un atributo (¿`su obligatoriedad?); sin embargo, también afirma —incluso en los mismos trabajos- que KELSEN está en lo cierto al sostener que la validez prescriptiva de cierta norma es relativa a la validez de otra norma. Estas dos afirmaciones son, evidentemente, contradictorias. Y aunque resulte sorprendente, la única explicación que se nos ocurre de esta contradicción es que BuLYGIN ha caído presa de un defecto que se ha cansado de atribuirle a otros: el no diferenciar con claridad entre normas y proposiciones normativas ( $c f r$. VON WRIGHT, 1963, p. 109). Es que hay dos sentidos en los que puede entenderse la idea de validez como fuerza obligatoria, esto es, el deber de cumplir con una norma: como una norma, una genuina prescripción que ordena cumplir con lo que cierta norma dispone, o como una proposición normativa que afirma la existencia de una norma jurídica que impone el deber de cumplir con otra. En el primer sentido, decir que una norma es válida no consiste en hacer ninguna afirmación sobre ella, sino en prescribir el deber de cumplirla. Este es el único sentido genuinamente prescriptivo de validez, y se trata además de una noción absoluta, porque decir que una norma es válida en este sentido no consiste en predicar de ella una cualidad relativa a lo preceptuado por otra norma: es prescribir que se la debe obedecer. En cambio, en el segundo sentido, decir que una norma es válida no implica comprometerse en absoluto con el deber de cumplir con ella, pues se trata de una afirmación que se limita a registrar la existencia de otra norma que impone el deber de cumplir con la primera. Por ello, esta es una noción descriptiva de validez como fuerza obligatoria, y es relativa a la existencia de otra norma. En sus trabajos más recientes sobre la cuestión BULYGIN no incurre ya en la indicada contradicción, sino que distingue un concepto relativo de validez como fuerza obligatoria de uno absoluto, lo cual parece sensato, pero afirma acto seguido que el concepto relativo presupone al absoluto. Hay un sentido en el que esto es correcto: decir que una norma N1 es válida, entendiendo por tal cosa que existe otra norma N2 que impone el deber de cumplirla, esto es, entendida como una proposición normativa, es una afirmación relativa, precisamente a la existencia de la norma N2, y esa noción de validez relativa presupone que, desde el punto de vista de N2, la norma N1 es válida en sentido genuinamente prescriptivo - esto es, absoluto-, dado que ella prescribe el deber de obedecerla. Claro que esto no es más que reconocer que la noción de proposición normativa presupone la noción de norma. Pero afirmar en sentido descriptivo que N1 tiene fuerza obligatoria porque N2 prescribe el deber de obedecerla no obliga a presuponer la validez como fuerza obligatoria de la norma N2 sino sólo su existencia. Lo contrario, tal como sostiene BULYGIN, conduciría o bien a requerir la existencia de una secuencia infinita de normas, en cuyo caso la noción de validez se tornaría ininteligible, o bien a aceptar que el último eslabón de la cadena debe ser una norma «absolutamente válida», lo cual sería tanto como sostener que no estamos dispuestos a admitir que se nos siga preguntando por su validez. 
BulYGIN estima que preguntarse si una norma es válida en el sentido de si posee fuerza obligatoria es tanto como preguntarse si existe un deber moral de obedecerla. Incluso asumiendo esto ad arguendo, y a menos que se considere que el positivismo sostiene una tesis normativa en lugar de una tesis conceptual, no se advierte por qué razón debería rechazarse el concepto de validez como fuerza obligatoria. Por cierto, admitir un concepto de validez como fuerza obligatoria no es lo mismo que predicar la validez en este sentido de las normas de cualquier sistema jurídico, lo que sí parecería comprometer la aceptación de la existencia de una relación necesaria entre Derecho y moral. El error central de la teoría kelseniana no consiste — como lo puntualiza Ross y parece aceptarlo BULYGIN — en asignarle al término «validez» un sentido prescriptivo, sino en confundir ese sentido con uno descriptivo. Dado que para KELSEN decir que una norma es válida es afirmar que ella posee fuerza obligatoria, tiene sentido que se pregunte por el fundamento de la validez de la primera norma positiva del sistema. Y como decir que una norma es válida significa además que ella es parte del sistema, no puede aceptar que una norma moral constituya el fundamento último de su validez, porque ello comprometería a conceder que la pertenencia de la constitución originaria y de todas las restantes normas al sistema dependería en última instancia de una norma moral, lo que claramente contradice la tesis básica del positivismo. Pero si los dos sentidos de validez se consideran conceptualmente independientes, tal como propone BULYGIN, el positivismo ya con sólo ello se encuentra suficientemente a salvo. No hay necesidad de abjurar de la validez como fuerza obligatoria: todo lo que el positivismo necesita es no confundir el problema de la validez como pertenencia con el problema de la validez como fuerza obligatoria ${ }^{26}$.

En síntesis, la expresión «validez» asume varios sentidos diferentes que no deben confundirse, pues de lo contrario pueden generarse muy serios problemas en la recons-

26 Como la justificación, que es una noción relativa — relativa a un cierto conjunto de razones—, la validez como fuerza obligatoria es relativa a un cierto conjunto de normas. Podría considerarse que la pregunta acerca de la validez jurídica como fuerza obligatoria de cierta norma N1 no se responde de manera completa identificando una norma N2 que impone el deber de obedecer N1, dado que se podría ahora inquirir por qué razón se debe obedecer N2, esto es, el problema puede replantearse con relación a la justificación de la norma justificante. A través de una serie de pasos en una cadena de validez en este sentido se arribará en última instancia a la constitución originaria del sistema. Pero una vez que se llega a ese punto, no existe por definición posibilidad de fundar su validez en otra norma jurídica. Si la validez jurídica en el sentido de fuerza obligatoria de una norma $\mathrm{N} 1$ equivale a la existencia en el sistema de otra norma jurídica N2 que prescribe el deber de obedecer N1, la pregunta acerca de la validez jurídica como fuerza obligatoria de la constitución originaria no tiene más sentido que la pregunta acerca del fundamento de su validez como pertenencia al sistema. No se trata, tal como lo presenta BuLYGIN, de que en este sentido de validez, una idea como la de la norma fundante kelseniana resulte insuficiente para justificar la validez jurídica como fuerza obligatoria de la constitución originaria: la constitución originaria claramente no es válida (ni inválida) en este sentido, por la sencilla razón de que no existe norma jurídica alguna que pudiera justificar el deber de cumplir con ella. Desde luego, tiene perfecto sentido preguntarse si se debe obedecer a la primera norma positiva de un sistema jurídico, pero esa pregunta no puede interpretarse sino como relativa al deber moral de obedecerla. Pero esto no es lo que nos preguntábamos al inquirir sobre la validez jurídica como fuerza obligatoria de la norma N1. Podríamos haber preguntado entonces por la justificación moral de N1, si bien por cierto habría sido un tanto extraño considerar que esa era una pregunta relativa a la validez jurídica de N1. Cuando se pregunta si cierta norma jurídica es válida en el sentido de si posee fuerza obligatoria, esa pregunta puede entenderse como relativa a su justificación jurídica o a su justificación moral, y estas dos cuestiones se refieren a diferentes marcos normativos que, desde una perspectiva positivista, no necesariamente tienen por qué coincidir. La idea de que una noción relativa de validez jurídica como fuerza obligatoria presupone una noción de validez absoluta, asimilada a la corrección moral, confunde una característica formal de las normas jurídicas, vinculada a la estructura jerárquica del Derecho, con una pregunta sustantiva acerca de su fuerza moral. 
trucción de los conceptos jurídicos más fundamentales. $\mathrm{Si}$ «validez» se interpreta como sinónimo de creación regular de una norma de conformidad con las pautas fijadas por otras normas, no todas las normas de un sistema jurídico pueden ser calificadas como válidas. Si la constitución es la norma que recoge en última instancia las pautas para la creación regular de las normas de carácter general, ella no es ni válida ni inválida en este sentido. $\mathrm{Si}$ «validez» se interpreta como sinónimo de pertenencia a un sistema, en cambio, todas las normas que componen un sistema jurídico serán normas válidas, pero deberá distinguirse entre ellas aquellas cuya pertenencia depende de su relación con otras normas del sistema (normas derivadas) y aquellas cuya pertenencia no depende de su relación con otras normas del sistema (normas originarias o no derivadas). Y, además, debe tenerse presente que predicar la validez de una norma en este sentido constituye solamente un juicio descriptivo que afirma que ella es parte de un conjunto más amplio de normas, sin que ello importe evaluación alguna respecto del deber de cumplirla o aplicarla. Por último, si «validez» se interpreta como sinónimo de fuerza obligatoria, la calificación resulta todavía problemática porque hay más de un sentido en el que puede hablarse de la fuerza obligatoria de las normas jurídicas. Decir que una norma es válida en este sentido puede leerse como una genuina norma que prescribe el deber de cumplir con ella, o bien como una proposición normativa que se limita a señalar que otra norma impone el deber de cumplir con ella. Y tanto en el primer caso como en el segundo, tales calificaciones pueden hacerse desde un punto de vista jurídico o desde un punto de vista moral. Contrariamente a lo que sostiene BuLYGIN, la fuerza obligatoria jurídica no debe confundirse con el deber moral de obedecer el Derecho y, además, ella admite una lectura prescriptiva y una descriptiva. De acuerdo con la primera, predicar la fuerza obligatoria jurídica de una norma equivale a prescribir el deber de obedecerla desde un punto de vista jurídico, mientras que, de acuerdo con la segunda, predicar la fuerza obligatoria jurídica de una norma equivale a afirmar que otra norma jurídica prescribe el deber de obedecerla. Esta última noción, descriptiva, es muy similar a la noción bulyginiana de aplicabilidad, sólo que concierne a los deberes jurídicos de los ciudadanos, no al de los jueces ${ }^{27}$.

27 Si el cargo de redundancia contra una norma que impone el deber de cumplir con otras normas resulta injustificado, o al menos tan justificado como una objeción semejante contra una norma que impone el deber de aplicar cierta norma a cierto caso, y si es perfectamente concebible una noción descriptiva de validez como fuerza obligatoria, y si una noción semejante no resulta en absoluto incompatible con una teoría positivista del Derecho, la propuesta de BULYGIN de sustituir la noción de validez como fuerza obligatoria por la de aplicabilidad parece innecesaria. De hecho, las diferencias entre la noción de aplicabilidad de BULYGIN y el concepto descriptivo de validez como fuerza obligatoria parecen poco relevantes. Considérese una norma N1 del tipo «quien cometa homicidio será castigado con una pena de diez años de prisión». Frente a ella una norma N2 que impusiera el deber de cumplirla obligaría a los jueces u otros órganos de aplicación a aplicarla a ciertos casos, puesto que la propia norma N1 tiene por destinatarios a tales órganos de aplicación. Si en lugar del deber de cumplirla, N2 impusiera el deber de aplicarla a determinados casos de homicidio, la situación no variaría. En consecuencia, con relación a normas de este tipo no parecería existir diferencia alguna entre el deber de cumplir y el deber de aplicar y, por ello, entre la noción de aplicabilidad y la de validez como fuerza obligatoria en el sentido considerado. Ahora considérese una norma N1 del tipo «el comprador está obligado a pagar el precio convenido por la cosa que adquiere». Frente a ella sí tendrían diferentes efectos una norma que imponga el deber de cumplirla y una que imponga el deber de aplicarla a ciertos casos. No obstante, y salvo ciertas situaciones excepcionales, si sus destinatarios están obligados a cumplirla, los órganos de aplicación estarán obligados a aplicarla en los casos relevantes y viceversa, de manera que, si bien conceptualmente diferenciables frente a este tipo de normas, las nociones de aplicabilidad y validez como fuerza obligatoria resultan, por lo menos ordinariamente, coextensivas. 


\section{AMBIGÜEDAD DE LA EXPRESIÓN «APLICABILIDAD»}

En el punto anterior se anticipó el sentido que acuerda BULYGIN a la expresión «aplicabilidad». De acuerdo con su análisis, puede decirse que una norma N1 es aplicable a cierto caso cuando existe otra norma N2 en el sistema jurídico que impone el deber de aplicarla a su respecto. Calificar a una norma como aplicable en este sentido no consiste en prescribir el deber de aplicarla (lo que podría considerarse una noción genuinamente prescriptiva de aplicabilidad), sino que se trata de una afirmación descriptiva y relativa a otra norma que integra el sistema jurídico. Resultaría superfluo que una norma disponga el deber de aplicar otra norma concreta a un caso concreto, de manera que en situaciones ordinarias no se necesita que una norma jurídica aclare que otra debe ser aplicada a los casos que ella regula: basta con que el legislador dicte ciertas normas regulando ciertos casos, pues se supone que los jueces y demás órganos de aplicación deben usar esas normas como fundamento de sus decisiones en los casos que ellas regulan. No obstante, como luego veremos, hay diversas situaciones en las que puede tener perfecto sentido el dictado de una norma que establezca sobre los jueces el deber de aplicar cierta clase de normas para la resolución de cierta clase de casos.

Ahora bien, la reconstrucción de BuLYGIN sólo recoge uno de los sentidos en los que suele emplearse la expresión «aplicabilidad» en el uso ordinario. De acuerdo con él, una norma aplicable es aquella que un juez debe aplicar a ciertos casos. No obstante, a veces se califican como aplicables aquellas normas que de hecho son empleadas como fundamento de la decisión frente a un caso, o bien las que resultan susceptibles de ser aplicadas a ciertos casos en virtud de la posesión de alguna propiedad relevante a tal fin. Para diferenciar estos últimos sentidos —fácticos, podríamos decir- del anterior, parece interesante tomar en cuenta una distinción propuesta por MORESO y NAVARRO: aquella que media entre lo que denominan «aplicabilidad externa» y «aplicabilidad interna» de las normas jurídicas ${ }^{28}$. La noción de aplicabilidad externa coincidiría básicamente con la noción que BULYGIN reconstruye: una norma N1 sería externamente aplicable en un tiempo $t$ respecto de cierto caso individual c, que es una instancia de un caso genérico C, si y sólo si otra norma N2 que pertenece al sistema jurídico en t obliga o permite aplicar N1 a los casos individuales que son instancias de C. En cambio, una norma $\mathrm{N}$ sería internamente aplicable en un tiempo t respecto de cierto caso individual c si y sólo si c es una instancia de un caso genérico C, y C es definido por los ámbitos de validez espacial, material, personal y temporal de $\mathrm{N}$.

Esta caracterización de la noción de aplicabilidad interna resulta, sin embargo, problemática. En primer lugar, recurrir a la idea kelseniana de los ámbitos de validez no parece muy esclarecedor si ella misma resulta altamente confusa. ¿Qué significa decir que una norma vale en cierto lugar, para cierto tiempo, respecto de ciertas personas y con relación a ciertas conductas, si «validez» es un término ambiguo en la Teoría Pura? Parecería más adecuado desembarazarse de esos problemas y decir, de manera más simple, que una norma es internamente aplicable a cierto caso si ella lo regula, esto es,

28 Cfr. MORESO y NAVARRO, 1997 y 1998. Desarrollos ulteriores en torno a estas nociones de aplicabilidad pueden consultarse en Navarro, Orunesu, Rodríguez y Sucar, 2000 y 2004. 
si el caso cae dentro del campo de significación de esa norma. Así, mientras la aplicabilidad externa sería una relación triádica entre dos normas y un caso, la aplicabilidad interna sería una relación diádica entre una norma y un caso.

Sin embargo, allí no terminan las dificultades: un segundo problema consiste en que la noción de aplicabilidad interna resulta por completo indeterminada si no se asume un cierto criterio de identidad de las normas. Determinar qué casos regula una norma y, por consiguiente, respecto de qué casos ella sería internamente aplicable, depende de lo que se entienda por norma. MORESO y NAVARRO consideran el hipotético caso de una norma N1 del Derecho irlandés que impone pena a quien provoque un aborto, y otra N2 del mismo sistema que establece que la norma anterior será aplicable a los abortos provocados dentro del territorio de Irlanda ${ }^{29}$. ¿Deberíamos decir que un aborto provocado en un país diferente sería un caso no regulado por N1, esto es, que $\mathrm{N} 1$ no es internamente aplicable a ese caso, o bien que N1 sí lo regula, pero que N2 restringe la aplicabilidad externa de $\mathrm{N} 1$ a los abortos provocados en el territorio irlandés? La respuesta de MORESO y NAVARRO a esta pregunta no es del todo clara: por una parte, citando a RAZ, parecen considerar que debería preferirse un criterio de identidad de las normas que las mantenga lo más cerca posible de las unidades textuales a través de las cuales ellas se expresan. Pero acto seguido aceptan que en realidad el material jurídico puede reconstruirse de muy diversos modos, y que no existe ningún test crucial y comúnmente aceptado para privilegiar alguno de ellos en particular. Claro que si esto fuera así, esto es, si no se encuentran razones para preferir algún criterio de identidad de las normas, entonces tampoco se dispone de ningún criterio para determinar qué casos regulan las normas y cuáles no y, por ello, para determinar a qué casos resultan internamente aplicables. A nuestro juicio, y contrariamente a lo que parecen sugerir MORESO y NAVARRO, resulta preferible en este punto una consideración holística de las normas, en el sentido de que, dado que las normas jurídicas integran complejos sistemas de normas, la identificación de cualquiera de ellas obliga a considerar la totalidad de las excepciones que restringen su alcance. Frente a un caso como el considerado por MORESO y NAVARRO nos parece que debería optarse por aquella reconstrucción según la cual la norma del Derecho irlandés no regula el caso de un aborto provocado fuera del territorio de Irlanda. Esta es, por otra parte, la reconstrucción más próxima a las intuiciones jurídicas usuales.

Ha existido una prolongada discusión en torno a las relaciones entre la aplicabilidad interna y la aplicabilidad externa de las normas. Aquí sólo diremos al respecto que parece más que sensato asumir que la aplicabilidad interna de una norma es condición necesaria de su aplicabilidad externa, pues la idea de que una norma pueda imponer sobre un juez el deber de utilizar como fundamento de su decisión frente a cierto caso una norma que no lo regula parece algo extravagante. Los pocos contraejemplos que se han sugerido no resultan convincentes ${ }^{30}$.

29 En MORESO y NAVARRo, 1997.

30 Se podría intentar justificar que en ciertas ocasiones los jueces tienen que fundar sus decisiones en normas que no son internamente aplicables al caso en cuestión considerando los supuestos de aplicación analógica de normas. Por ejemplo, el art. 1.492 del Código Civil argentino establece que el contrato de permuta se rige por las disposiciones concernientes a la compraventa en todo lo que no se hubiere determinado especialmente a su respecto. Dado que la permuta obviamente no es una compraventa, se podría pensar que esta norma establece el deber de aplicar las normas de la compraventa a ciertos casos que ellas no regulan. Sin embargo, 
En cambio, no puede decirse que la aplicabilidad interna sea condición suficiente de la aplicabilidad externa. Ocurre que al menos no puede descartarse que exista en el marco de cierto sistema jurídico más de una norma que resulte internamente aplicable con relación a un mismo caso, y que ellas puedan establecer soluciones incompatibles a su respecto. En un supuesto de genuina contradicción normativa, las normas en conflicto resultan internamente aplicables, pero el juez debe utilizar una como fundamento de su decisión, sólo que no existen en el sistema pautas que le indiquen cuál es la que debe emplear, de modo que una de ellas no puede ser externamente aplicable. En consecuencia, no es posible descartar que, pese a que una norma sea internamente aplicable a un caso, no obstante ello no determine un deber concluyente para un juez.

Parece importante explorar, al menos someramente, las relaciones entre estas nociones de aplicabilidad y las de validez. En primer lugar, ni la aplicabilidad interna ni la aplicabilidad externa de una norma dependen de su validez en el sentido de creación regular de acuerdo con las pautas fijadas por el propio sistema al cual ellas pertenecen o por cualquier otro. Toda norma necesariamente regulará ciertos casos de acuerdo con su alcance o campo de significación, con independencia de si ha sido o no creada regularmente, y si otra norma jurídica establece sobre los jueces el deber de aplicarla a ciertos casos, ella resultará externamente aplicable aún cuando no haya sido creada regularmente. La validez como creación regular no es condición suficiente ni necesaria ni de la aplicabilidad interna ni de la aplicabilidad externa.

En segundo lugar, tampoco la validez como pertenencia a un sistema jurídico constituye por sí sola una condición necesaria o suficiente ni de su aplicabilidad interna ni de su aplicabilidad externa respecto de cierto caso. Sin embargo, existen otras conexiones más complejas entre la aplicabilidad externa y la pertenencia al sistema. Por una parte, tal como lo señala correctamente BuLYGIN, la aplicabilidad externa de la norma N1 depende de la pertenencia al sistema jurídico de la norma N2 que impone el deber de aplicarla a cierto caso ${ }^{31}$. Por otra parte, si una norma pertenece a un sistema jurídico y resulta internamente aplicable a ciertos casos, ello constituye ordinariamente

esa conclusión es incorrecta. Supóngase un caso en el que se ha celebrado un contrato de permuta entre las partes, y se requiere de un juez una decisión, por ejemplo, acerca de si el actor tiene o no derecho a reclamar la resolución del contrato y la restitución de la cosa por él entregada cuando la contraparte no ha cumplido con su contraprestación, y que no existe una cláusula específica al respecto. El juez no podría justificar su decisión sobre la exclusiva base de una norma que consagrara el pacto comisorio tácito para los contratos de compraventa, por la sencilla razón de que, como el caso individual aludido no es una instancia del caso genérico contemplado por la norma que regula el pacto comisorio en la compraventa, no podría derivarse de ella solución alguna para el caso a decidir. Para poder hacerlo es menester de algún modo integrar al razonamiento justificatorio lo dispuesto por un artículo como el 1.492 del Código Civil argentino, cosa que podría hacerse considerando: a) que la norma en cuestión autoriza al juez a aplicar a los casos de permuta normas generales que no integran el sistema y que el juez debe crear al efecto en analogía con lo preceptuado por las normas previstas para la compraventa; $b$ ) que el artículo en cuestión, por razones de técnica legislativa, evita reproducir para la permuta todas las disposiciones ya consagradas para los contratos de compraventa que no resulten excluidas en virtud de las diferencias que median entre ambos tipos de contrato, o $c$ ) que el art. 1.492 autoriza al juez a reputar relevantes las semejanzas existentes entre los contratos de compraventa y los contratos de permuta, a fin de correlacionar a todos los casos genéricos de permuta (salvo los expresamente regulados) las soluciones normativas especificadas para los casos genéricos de compraventa. En ninguna de estas tres alternativas de reconstrucción es la propia norma que regula el pacto comisorio en la compraventa la que permite justificar la decisión del juez, por lo que ninguna de ellas abona la conclusión de que se declara externamente aplicable a un caso una norma que no lo regula.

$$
{ }^{31} \text { Cfr. Bulygin, } 1982 .
$$


una condición suficiente para que los jueces tengan el deber de aplicarla. La excepción está dada por los supuestos de contradicciones normativas, en los que, como se dijo, existiría más de una norma internamente aplicable, de modo que no todas ellas podrían resultar externamente aplicables. MORESO y NAVARRO han explorado como otras posibles excepciones en el mismo sentido a las normas en vacatio legis y a los supuestos de suspensión de garantías constitucionales en situaciones de excepción —estado de sitio-. A su juicio, se trataría de normas que pertenecen al sistema y regulan ciertos casos pero que no resultan externamente aplicables a ellos ${ }^{32}$. No obstante, y por las razones ya señaladas, en ambas situaciones parece más adecuado considerar que las normas en cuestión no son externamente aplicables porque no los regulan, esto es, porque no son internamente aplicables.

La pertenencia al sistema de una norma - conjuntamente con su aplicabilidad interna - no es, sin embargo, una condición necesaria de su aplicabilidad externa a cierto caso. Puede ocurrir que una norma jurídica N2 imponga sobre los jueces el deber de aplicar una norma N1 a ciertos casos aunque esta última no pertenezca al sistema jurídico en cuestión, siempre que regule el caso ${ }^{33}$. Esto es lo que ocurre en los supuestos de ultraactividad de las normas derogadas y en los casos de conflicto de Derecho internacional privado. En ambos supuestos el sistema jurídico remite a normas extrasistemáticas a las que atribuye aplicabilidad respecto de ciertos casos debido a que el sistema no contiene ninguna norma que resulte internamente aplicable a ellos.

Por último, desde una concepción positivista del Derecho, ni la aplicabilidad interna ni la aplicabilidad externa de una norma jurídica dependen de su validez como fuerza obligatoria moral. La fuerza obligatoria jurídica, entendida en sentido descriptivo como la existencia de otra norma jurídica que obliga a cumplir con lo que ella dispone, es una noción íntimamente emparentada con la aplicabilidad externa, tal como ya se expresó. De hecho, al menos a primera vista parecería que toda norma externamente aplicable respecto de cierto caso es una norma que posee fuerza obligatoria en este sentido, y viceversa.

\section{LAS DIFICULTADES DE LA RECONSTRUCCIÓN BAJO ANÁLISIS}

Despreciando por ahora ciertas diferencias que luego puntualizaremos, las posturas defendidas por REQUeJo PAGÉs y GIL DOMínGUEZ respecto de las relaciones entre el Derecho nacional y las normas del Derecho internacional que reseñáramos en el primer punto de este trabajo pueden sintetizarse en la defensa de las siguientes cinco tesis:

1. En todo Estado nacional resultan aplicables ciertas normas.

2. La aplicabilidad de tales normas presupone su validez.

3. Las condiciones de validez de algunas de esas normas — las internas- son determinadas por la constitución del Estado de que se trate o por normas derivadas de ella.

32 Cfr. MORESO y NaVARro, 1997.

33 Cfr. Bulygin, 1982, y Moreso y NAVArro, 1997 y 1998. La misma idea se encuentra ya en RaZ, 1979b, y más recientemente en RAZ, 2004. 
4. Las restantes - las internacionales - son aplicables porque así lo dispone la constitución, pese a que sus condiciones de validez no están determinadas por ella.

5. Todas esas normas integran el sistema jurídico correspondiente al Estado nacional en cuestión.

De esta reconstrucción simplificada no parecen problemáticas las tesis 1,3 y 4 , esto es, que de todas las normas que resultan aplicables en un cierto Estado, algunas derivan su validez de la constitución mientras que otras son aplicables pese a que sus condiciones de validez no derivan de la constitución. Pero de estas ideas y, más básicamente, de la propuesta fundamental de diferenciar validez y aplicabilidad, parecería natural concluir que sólo integran un ordenamiento jurídico nacional las normas válidas, y que las normas internacionales pueden resultar aplicables incluso aunque no integren el sistema. No obstante, esto contradice tanto la tesis 2 como la tesis 5 .

De acuerdo con la tesis 2, todas las normas aplicables han de ser válidas. Pese a algunas vacilaciones, parecería que por aplicabilidad tanto REQUEJO PAGÉS como GIL DOMÍNGUEZ interpretan algo parecido a lo que, siguiendo a MORESO y NAVARRO, calificáramos como aplicabilidad externa. En cuanto a la validez, en cambio, cuál sea la noción que aquí se emplea es algo mucho más complejo. En la reconstrucción de REQUEJO PAGÉS-GIL DOMíngUEZ, claramente no puede considerarse que la validez sea entendida como pertenencia de una norma al sistema, dado que si ese fuera el caso, de acuerdo con las tesis 3 y 4 sólo las normas nacionales pertenecerían al Derecho interno, no así las internacionales, lo que contradiría la tesis 5 . Pero sólo si validez se interpreta como sinónimo de pertenencia a un sistema jurídico puede sostenerse que la constitución es una norma válida. En cambio, si se interpreta a la validez como sinónimo de fuerza obligatoria o creación regular, decir que la constitución es una norma válida resulta problemático. En el sentido de creación regular, la constitución no es válida, pues si bien podría sostenerse que la constitución vigente en un cierto Estado nacional es válida en este sentido pues fue creada de conformidad con un procedimiento de reforma establecido en una constitución anterior, un razonamiento semejante conduce inexorablemente a una primera constitución histórica que no satisface esta condición. En el primer sentido, esto es, como fuerza obligatoria, tampoco puede decirse que la constitución sea una norma jurídicamente válida. Puede, por cierto, inquirirse sobre el deber de cumplir con ella, pero claramente esto obliga a adentrarse en consideraciones de legitimidad política o aceptabilidad moral, mientras que de las restantes normas cuya validez se deriva de la constitución o de las condiciones fijadas por el Derecho internacional, puede hablarse de una fuerza obligatoria jurídica, esto es, derivada de normas jurídicas y no de pautas extrajurídicas de evaluación normativa, lo que no es predicable de la propia constitución.

REQUEJO PAGÉS, sin dar una definición explícita, parece entender por «validez» alternativamente - como si fueran equivalentes - creación regular y fuerza obligatoria. Por su parte, GIL DOMínGUEZ sostiene expresamente que una norma sería «válida o inválida siempre que se adecue a los postulados de producción jurídica» ${ }^{34}$ establecidos por una norma superior. Más allá de que, así presentada, la caracterización es deficiente, puesto que sólo la validez de una norma, no su invalidez, depende de su adecuación

34 Gil DomíngueZ, 2004, p. 99. 
a las pautas de creación normativa previstas en otra norma, ello supone claramente adoptar el sentido de validez como creación regular. Sin embargo, GIL DomínguEz afirma paralelamente que la validez permitiría determinar el conjunto de normas que integran un sistema, con lo que parece identificar validez con pertenencia.

Ahora bien, si por validez se entiende la creación regular de una norma de conformidad con las pautas de creación normativa establecidas por el propio sistema, no podría sostenerse que todas las normas aplicables deben ser válidas, ya que ello resultaría incompatible con la tesis 4: las normas internacionales, se sostiene, se consideran aplicables pese a que ellas no son válidas en este sentido. Pero entonces, ¿bajo qué acepción de validez podría ser correcto lo que afirma la tesis 2 ? Si por validez se interpreta, en un sentido más amplio, la creación regular de una norma de conformidad con lo establecido por otra norma, sea que esta última integre o no el sistema de referencia, lo que afirma la tesis 2 no constituye una exigencia conceptual que se derive de la noción de aplicabilidad: tanto la constitución como cualquier norma de rango infraconstitucional podrían declarar aplicables otras normas pese a que ellas no hayan sido creadas regularmente ni de acuerdo con pautas sistemáticas ni de acuerdo con pautas extrasistemáticas. Dado que la tesis 2 no puede leerse como si expresara un requisito conceptual, quizás podría interpretársela como si estableciera una exigencia normativa, esto es, que las normas de un cierto sistema jurídico no deben declarar aplicables normas que no hayan sido creadas regularmente de conformidad con alguna otra pauta normativa, sistemática o extrasistemática. Pero esta interpretación normativa también resulta controvertible. Supóngase un caso en el que la constitución declara aplicable un convenio internacional sobre cuyas condiciones de validez de acuerdo con las normas del Derecho internacional existe controversia debido a algún vicio relativo a su creación, o debido a que todavía no ha recibido la totalidad de las ratificaciones que permitan considerarlo válido en sede internacional. Frente a un supuesto semejante, la tesis 2 en esta lectura normativa determinaría que la remisión constitucional sólo resultaría operativa si la norma a la que se efectúa la remisión es válida según el Derecho internacional. Ahora bien, ¿por qué habría que optar necesariamente por esa solución en lugar de considerar aplicable a la norma en cuestión pese a las deficiencias en cuanto a su validez? El punto parece, por lo menos, seriamente controvertible.

El que la creación regular, juzgada según pautas de un sistema diferente, no parece condición necesaria de la aplicabilidad resulta aún más claro si se admite, tal como muchos autores lo hacen, que en diversas circunstancias los sistemas jurídicos contemporáneos declaran aplicables a ciertos casos normas morales, pues parece evidente que las normas morales no son válidas en el sentido de haber sido creadas mediante procedimientos establecidos en otras normas. Igual conclusión parece seguirse incluso respecto de la creación regular juzgada según pautas del propio sistema si se admite que una norma puede resultar aplicable a cierto caso pese a haber sido derogada. Considérense los supuestos de ultraactividad de las normas penales que ya han sido derogadas a ciertos casos en virtud de que establecen una solución más benigna para el imputado en comparación con la norma posterior que ha venido a sustituirlas. En tal caso, si bien la norma puede haber sido creada regularmente de conformidad con las pautas de creación normativa que el propio sistema determina y, en tal sentido, habría sido introducida válidamente en el sistema, también habría sido derogada regularmente según esas mismas pautas, por lo que igualmente habría sido eliminada válidamente 
del sistema. Resultaría por ello muy extraño sostener que, pese a su derogación, sigue siendo una norma válida. Pero su invalidez no obsta a su aplicabilidad.

De acuerdo con la tesis 5 , por su parte, un sistema jurídico nacional está conformado por todas las normas aplicables. La validez, entendida en el sentido amplio antes considerado, esto es, como creación regular según pautas fijadas por otras normas, sea que ellas integren o no el sistema, sería en todo caso una condición necesaria pero no suficiente para considerar que una norma es parte del sistema — con los problemas ya apuntados que esto conlleva-. Ahora, un sistema, en la acepción corriente de tal expresión, es un conjunto ordenado, es decir, un conjunto tal que su identidad no depende exclusivamente de la identidad de sus elementos componentes, sino de al menos una relación que vincula a tales elementos. Por consiguiente, para concebir a un conjunto de normas como un sistema es preciso identificar al menos una relación entre ellas que defina su carácter sistemático ${ }^{35}$. De conformidad con la tesis 5 , la cualidad relacional que dotaría al sistema jurídico nacional de su carácter sistemático sería la aplicabilidad de sus normas. Ella constituiría, tal como lo presenta GIL DOMÍNGUEZ, la propiedad «integradora» que permitiría articular las normas cuyas condiciones de validez derivan de la Constitución y las del Derecho internacional, como dos subsistemas dentro del mismo ordenamiento jurídico nacional.

Resulta novedoso el que se tome a la noción de aplicabilidad como base para la reconstrucción sistemática del material jurídico. Por cierto, nada obsta a reconstruir como un sistema al conjunto de las normas que resultan aplicables en cierta jurisdicción estatal. Lo que sí parece problemático es identificar ese sistema con un ordenamiento jurídico nacional. Si el considerar aplicables en el ámbito interno a las normas del Derecho internacional obliga a reputarlas miembros del Derecho nacional que las recepta, no quedaría nada parecido a un Derecho internacional que pueda estimarse como un sistema jurídico independiente. Esto es lo que parece reconocer REQUEJO PAGÉS cuando sostiene que el Derecho internacional sería algo así como un «sistema incompleto», pues sólo podría determinar la validez de sus normas, no así su aplicabilidad, la que sería establecida por los ordenamientos jurídicos nacionales ${ }^{36}$. Pero en sentido estricto, si lo que dota a un conjunto de normas de su carácter sistemático es la aplicabilidad, y si la aplicabilidad de las normas internacionales es establecida por los sistemas jurídicos nacionales, el Derecho internacional no sería un sistema jurídico incompleto: simplemente no sería un sistema jurídico. GIL DomínguEZ, en cambio, afirma que el Derecho nacional y el Derecho internacional serían dos sistemas jurídicos con existencia independiente, y que la validez sería en principio lo que permitiría determinar el conjunto de las normas que integran un sistema jurídico. Pero también sostiene que la aplicabilidad sería una condición en virtud de la cual una norma formaría parte de un ordenamiento jurídico sin depender para ello de que su validez se derive de la constitución. Como parece obvio, si lo segundo es correcto, no es la validez lo que determina la pertenencia de una norma a un sistema y, como se dijo, el Derecho internacional no sería un sistema jurídico independiente. Y si en cambio esto último es el caso, y el carácter sistemático está determinado por la validez, la aplicabilidad no puede ser condición suficiente de la pertenencia de una norma al sistema. No

\footnotetext{
35 Cfr. Caracciolo, 1988, p. 12.

36 Cfr. Requejo Pagés, 1992, p. 47.
} 
hay modo de integrar coherentemente estas ideas, porque si pretendiera responderse que en realidad ni la validez por sí sola ni la aplicabilidad por sí sola determinan el carácter sistemático de un ordenamiento jurídico nacional, sino que la primera es relevante para la integración de las normas del Derecho interno y la segunda para la integración de las normas del Derecho internacional, no habría justificación alguna para considerar que estos dos conjuntos de normas no constituyen dos sistemas diferentes sino uno solo.

Lo anterior, con todo, no es más que una cuestión de detalle si se repara en una consecuencia mucho más grave de la tesis 5 . Si el conjunto de las normas aplicables en cierta jurisdicción nacional se identifica con un ordenamiento jurídico nacional, no sólo resulta que no será posible asignar carácter autónomo al Derecho internacional: ni siquiera será posible contar con un criterio satisfactorio para diferenciar distintos sistemas jurídicos nacionales. En efecto, considérense los casos de conflicto del Derecho internacional privado. En muchos supuestos las normas de un Derecho nacional (sean o no de rango constitucional) remiten a normas de sistemas jurídicos extranjeros cuando un caso presenta algún punto de conexión relevante con él. Al igual de lo que ocurre con un convenio internacional, las normas de los sistemas jurídicos extranjeros a las que el Derecho nacional remite no son válidas de conformidad con las pautas de creación normativa del sistema jurídico que efectúa la remisión; si ellas han sido creadas regularmente, sus condiciones de validez deben ser juzgadas en función de lo que dispongan pautas extrasistemáticas. No obstante, en aquellos casos que se presentan ante los tribunales de cierto Estado en los que se verifique un punto de conexión relevante con normas extranjeras, tales normas serán sin duda aplicables. Si la aplicabilidad es lo que determina la pertenencia de una norma a un sistema jurídico nacional, entonces las normas de cualquier Derecho extranjero que pudieran resultar aplicables en casos de conflicto serían normas que integrarían el sistema nacional donde resulten aplicables. Por ejemplo, el Derecho argentino dispone que las sucesiones se rigen por la ley del último domicilio del causante. Si se abre en Argentina la sucesión de una persona con último domicilio en España, todo el Derecho sucesorio español sería potencialmente aplicable en nuestro país y, por esa razón, de acuerdo con esta reconstrucción sería parte del Derecho argentino. Pero esto es sencillamente absurdo porque implicaría que cualquier norma de cualquier sistema jurídico extranjero podría ser parte de cualquier ordenamiento jurídico nacional, lo cual significaría que no existe criterio alguno para diferenciar distintos sistemas jurídicos nacionales.

\section{HACIA UNA RECONSTRUCCIÓN ALTERNATIVA}

Si las observaciones formuladas en el punto anterior son atendibles, debería considerarse la posibilidad de modificar la reconstrucción de REQUeJO PAGÉS y GIL DOMÍNGUEZ de un modo parecido al siguiente:

1. En todo Estado nacional resultan aplicables ciertas normas.

2. Algunas de esas normas - las internas - son aplicables porque son normas válidas, esto es, porque pertenecen al sistema delimitado por la constitución del Estado de que se trate. 
3. Las restantes - las internacionales - son aplicables ya sea porque la constitución las integra como normas del sistema, ya sea porque las declara aplicables aunque no pertenezcan al sistema.

La discusión en torno a las relaciones entre los Derechos nacionales y el Derecho internacional se ha presentado tradicionalmente ${ }^{37}$ como la necesidad de optar entre tres alternativas que parecen comportarse como conjuntamente exhaustivas y mutuamente excluyentes: el dualismo o pluralismo, según el cual los Derechos nacionales y el Derecho internacional conformarían sistemas jurídicos independientes; el monismo de corte nacional, según el cual las normas internacionales no constituirían un sistema independiente sino que sólo serían parte de aquellos sistemas jurídicos nacionales que así lo reconozcan, y el monismo de corte internacional, de acuerdo con el cual los Derechos nacionales serían subsistemas dentro de un único sistema jurídico global, en el que las normas del Derecho internacional ocuparían la máxima jerarquía. No resulta del todo claro si quienes defienden cada una de estas tesis pretenden con ellas describir las relaciones existentes entre el Derecho internacional y los Derechos nacionales o si, en cambio, asumen un carácter prescriptivo o ideológico, esto es, postulan aquel estado de cosas que se reputa deseable. En el primer caso, la tesis monista de corte nacional no parece dar cuenta de manera satisfactoria del innegable proceso histórico de desarrollo del Derecho internacional a partir del pasado siglo y de las concomitantes restricciones a las soberanías nacionales. De todos modos, y no obstante lo anterior, la tesis monista internacional interpretada de este modo parece todavía decididamente falsa. En el segundo caso, la tesis monista nacional parece excesivamente conservadora. El monismo internacional, en cambio, se presenta como la opción más atractiva, siempre - claro está- que el reconocimiento de la supremacía del Derecho internacional como límite a las competencias de los Derechos nacionales se extienda a todos los Estados, no sólo a los menos poderosos, tal como parece ser el caso hoy día.

Pero incluso adoptando su lectura descriptiva, la distinción entre validez como pertenencia y validez como fuerza obligatoria o aplicabilidad, obliga a diferenciar dos versiones de las tesis monistas y dualistas, según que ellas se entiendan como relativas a lo primero o a lo segundo:

Tesis dualista de la pertenencia (DP): Las condiciones de pertenencia de normas al Derecho internacional y a los Derechos nacionales son independientes, pues ni las del primero están determinadas por los Derechos nacionales ni las de los segundos están determinadas por el Derecho internacional.

Tesis monista nacional de la pertenencia (MNP): Las normas del Derecho internacional no conforman un sistema independiente de los Derechos nacionales: ellas sólo pertenecen a los sistemas nacionales en la medida en que así lo determinen los criterios de pertenencia de estos últimos.

Tesis monista internacional de la pertenencia (MIP): Las normas de los Derechos nacionales conforman subsistemas dentro del Derecho internacional: este último determina las condiciones de pertenencia de normas a tales subsistemas.

37 En la actualidad los teóricos del Derecho internacional y comunitario son más bien proclives a sostener que estas doctrinas ya no ocupan el centro de la escena, no obstante lo cual no hay curso de Derecho internacional que no comience por exponerlas (cfr. TRAVIESO, 1999, p. 66). 
Tesis dualista de la aplicabilidad (DA): Las condiciones de aplicabilidad de las normas en el Derecho internacional y en los Derechos nacionales son independientes, pues ni las del primero están determinadas por los Derechos nacionales ni las de los segundos están determinadas por el Derecho internacional.

Tesis monista nacional de la aplicabilidad (MNA): La aplicabilidad de las normas del Derecho internacional no es independiente de los Derechos nacionales: ellas sólo son aplicables en los sistemas nacionales en la medida en que así lo determinen los criterios de aplicabilidad de estos últimos.

Tesis monista internacional de la aplicabilidad (MIA): La aplicabilidad de las normas de los Derechos nacionales no es independiente del Derecho internacional, pues ella está determinada por este último.

Estas seis diferentes tesis permiten, a su vez, considerar la plausibilidad de nueve modelos diferentes de reconstrucción de las relaciones entre los Derechos nacionales y el Derecho internacional:

1. MIP-MIA: El Derecho internacional determina tanto la pertenencia de normas a los sistemas nacionales (estos últimos no son más que subsistemas dentro del orden global que conforma el Derecho internacional) como sus condiciones de aplicabilidad.

2. MIP-MNA: Las normas de los Derechos nacionales conforman subsistemas dentro del Derecho internacional, pero las normas internacionales no tienen aplicabilidad sino en la medida de su reconocimiento por los sistemas nacionales.

3. MIP-DA: Las normas de los Derechos nacionales conforman subsistemas dentro del Derecho internacional, pero en cada uno de estos dos ámbitos existen condiciones de aplicabilidad de normas que resultan independientes.

4. MNP-MIA: No existe un Derecho internacional como sistema independiente de los Derechos nacionales: sus normas sólo pertenecen a los sistemas nacionales en la medida en que así lo determinen los criterios de pertenencia de estos últimos. No obstante, la aplicabilidad de las normas en los Derechos nacionales está determinada por el Derecho internacional (este modelo parece inconsistente.)

5. MNP-MNA: Las normas del Derecho internacional no tienen ninguna existencia independiente de lo que dispongan los Derechos nacionales. Estos últimos determinan cuándo una norma internacional pertenece a su sistema nacional tanto como en qué casos ellas resultan aplicables.

6. MNP-DA: Las normas del Derecho internacional no conforman un sistema independiente de los Derechos nacionales, sino que sólo pertenecen a los sistemas nacionales en la medida en que así lo determinen los criterios de pertenencia de estos últimos. No obstante, existen criterios de aplicabilidad de las normas internacionales que son independientes de los criterios de aplicabilidad de los sistemas nacionales. (Este modelo parece inconsistente.)

7. DP-MIA: Las condiciones de pertenencia de normas al Derecho internacional y a los Derechos nacionales son independientes; sin embargo, la aplicabilidad de las normas de los Derechos nacionales está determinada por el Derecho internacional.

8. DP-MNA: Las condiciones de pertenencia de normas al Derecho internacional y a los Derechos nacionales son independientes; no obstante, las normas del De- 
recho internacional no tienen otra aplicabilidad que la que le reconozcan los sistemas nacionales.

9. DP-DA: El Derecho internacional y los Derechos nacionales son independientes tanto en lo que atañe a las condiciones de pertenencia como a las condiciones de aplicabilidad de sus respectivas normas.

Como puede apreciarse, el monismo internacional y el dualismo, como tesis relativas a la pertenencia, son prima facie compatibles con todas las posiciones posibles en lo que respecta a la aplicabilidad. En cambio, el monismo nacional, como tesis relativa a la pertenencia, es incompatible con cualquier otra posición que no sea monista nacional en cuanto a la aplicabilidad.

Efectuando la corrección sugerida de la reconstrucción bajo examen, la posición de REQUeJo PAGÉs parecería adecuarse al modelo 8, esto es, dualismo en cuanto a la pertenencia y monismo de carácter nacional en cuanto a la aplicabilidad. Desde este punto de vista, los tratados internacionales de derechos humanos no podrían condicionar la validez de las normas del Derecho interno, de manera que, por caso, un conflicto entre un tratado internacional y una ley posterior no determinaría la invalidez de la segunda, sino que ambas serían normas válidas pero la internacional gozaría de aplicabilidad preferente ${ }^{38}$.

Más difícil resulta encuadrar la postura de GIL DomínguEz. Su adscripción a las ideas de REQUEJO PAGÉs parece orientada a proponer — desde un punto de vista ideológico- que la aplicación de las normas del Derecho internacional de los derechos humanos no tenga que pasar por ningún filtro en el ámbito nacional, esto es, remitiendo en todos los casos a las pautas de interpretación de los órganos internacionales, lo que implicaría una restricción a los jueces en su potestad de control de constitucionalidad en materia de tratados internacionales, en el sentido de que sólo podrían verificar su aplicabilidad, no su validez ${ }^{39}$. Por otra parte, es justamente la pretensión de no nacionalizar el Derecho internacional lo que lo mueve a adoptar esta concepción, pero GIL DOMínguEZ no lo hace de modo totalmente consecuente, pues no hace jugar con tal firmeza normas como la que REQUEJO PAGÉs deriva del art. 27 de la Convención de Viena sobre Derecho de los Tratados ${ }^{40}$.

Además, y a diferencia de REQUEJO PAGÉs, las normas internacionales de tutela de los derechos humanos declaradas aplicables en sede interna, junto con la constitución,

38 Esta aplicabilidad preferente se justificaría en una particular interpretación del art. 27 de la Convención de Viena sobre Derecho de los Tratados. Ella es compartida por nuestra CSJN desde el caso Ekmekdjián, citado en nota 11, y con mayor precisión en Fibraca Constructora SCA c/ Comisión Tecnica Mixta de Salto Grande (Fallos, 316:1669, considerando 5), donde se sostuvo que «La necesaria aplicación de este artículo impone a los órganos del Estado argentino —una vez asegurados los principios de Derecho público constitucionalesasignar primacía a los tratados ante un eventual conflicto con cualquier norma interna contraria». En contra puede consultarse FUENTES TORRIJO, 2006.

${ }^{39}$ Cfr. GIL Domínguez, 2007, p. 22. En contra, y pacíficamente, la doctrina y la legislación nacional (sobre la base de lo dispuesto por el art. 21 de la Ley 48) han considerado que los jueces en nuestro sistema son los órganos habilitados en última instancia para verificar la compatibilidad de los tratados internacionales con la Constitución ( $c f r$. VANOSSI y Dalla Vía, 2000, pp. 205-214). Asimismo, cabe entender que ello ha sido asumido por la CSJN aún antes de la reforma de 1994 in re Fibraca, citado en la nota anterior, y ratificado posteriormente en Cafés La Virginia (Fallos, 317:1282), por lo que la tesis de GIL DomíngUEZ no parece funcionar en el nivel descriptivo, al menos con relación a todo tipo de tratado internacional.

${ }^{40}$ Cfr. Gil Domínguez, 2007, pp. 42-43. 
conformarían para GIL Domínguez el parámetro de verificación de la validez de las normas nacionales de inferior jerarquía. Siendo ello así, la validez de las normas de fuente interna no estaría completamente determinada por la constitución: ella sólo determinaría un conjunto de condiciones necesarias pero no suficientes para la validez de las normas infraconstitucionales, ya que para ser válidas estas últimas deberían además resultar compatibles con las normas internacionales declaradas aplicables. Si se acepta esto último, ya no puede decirse que un sistema jurídico nacional se descompone en dos subsistemas, el de las normas de Derecho interno, cuya validez estaría determinada por la constitución, y el de las normas internacionales, cuya aplicabilidad sería determinada por la constitución pese a que sus condiciones de validez dependerían del Derecho internacional. Porque si la validez de las normas del Derecho interno depende al menos parcialmente de su compatibilidad con normas internacionales cuya propia validez no es determinada por la constitución sino por el Derecho internacional, esta posición se correspondería con el modelo 2 , esto es, monismo de carácter internacional en cuanto a la pertenencia y monismo de carácter nacional en cuanto a la aplicabilidad.

En lo que concierne al caso argentino, con respecto al problema de si las normas del Derecho internacional de los derechos humanos declaradas aplicables por nuestra Constitución tienen ese carácter porque integran nuestro sistema jurídico o revisten el carácter de normas aplicables pese a no formar parte de él, creemos que no debería descartarse a priori el examen de la plausibilidad de cada una de estas dos reconstrucciones. Si bien frente a expresiones como las contenidas en los arts. 31, 75 inciso 22 y 116 de la Constitución Nacional, parece muy difícil sostener que ninguna norma del Derecho internacional integra el ordenamiento jurídico nacional, el punto en el que resulta relevante la diferencia entre las dos reconstrucciones está dado por el modo de resolver posibles conflictos entre las normas de fuente internacional y las de fuente interna. En Argentina, si se estima - tal como lo hace GIL DomíngUEZ- que las normas internacionales de tutela de los derechos humanos que revisten jerarquía constitucional han de ser tomadas en cuenta para evaluar la validez de las normas de jerarquía inferior, esto es, que un posible conflicto de tales características debe resolverse declarando inválida a la norma inferior y no meramente estimándola inaplicable, la distinción entre validez y aplicabilidad se vuelve irrelevante para examinar el problema, por lo que debería considerarse que las normas internacionales integran el sistema nacional. Por otra parte, debería resultar claro que para quienes rechazan una concepción monista nacional respecto de las relaciones entre el Derecho internacional y los derechos nacionales en cuanto a la pertenencia, deviene pragmáticamente contradictorio sostener que para ser aplicables en el Derecho interno tales normas deben ser consideradas miembros de los sistemas jurídicos nacionales, de modo que lo sensato sería reputarlas aplicables pese a no ser parte de los derechos nacionales, pero entonces los posibles conflictos con el Derecho interno deberían resolverse en el nivel de la aplicabilidad y no en el de la validez.

En este sentido, las previsiones normativas de los arts. 27, 31, 75 inciso 22 y 116 de la Constitución argentina, si bien hacen alusión a los tratados internacionales como normas diferentes de las restantes de fuente nacional, las condicionan a su aprobación por las autoridades nacionales que conducen las relaciones internacionales y al respeto de una serie de principios de Derecho público positivizados en la misma Constitución, favoreciendo de tal suerte el control judicial de constitucionalidad de los tratados internacionales (al menos de aquellos que carecen de jerarquía constitucional de acuerdo 
con el segundo y el tercer párrafo del art. 75 inciso 22 de la Constitución Nacional). Menos clara es la situación de las normas no convencionales del Derecho internacional, que pueden derivarse de la costumbre internacional, cuya aplicación obligatoria en el Derecho interno sólo puede justificarse sobre la base de una interpretación muy forzada del art. 118 de la Constitución Nacional ${ }^{41}$.

En tanto no se consolide de manera global el reconocimiento de la supremacía del Derecho internacional sobre los derechos nacionales, de modo que resulte adecuada la reconstrucción que ofrece el monismo internacional de la pertenencia, los derechos nacionales conservarán, como hoy es corriente, normas relativas a la recepción del Derecho internacional en el Derecho interno.

En la interpretación del ex Ministro de la Corte Suprema Antonio Boggiano, plasmada en su voto en las causas Arancibia Clavel y Simón, deberían diferenciarse cuatro formas básicas en las que el Derecho interno puede acoger a las normas internacionales: el sistema de incorporación, el de recepción, el de adaptación y el de referencia. En el sistema de incorporación el legislador local nacionaliza al Derecho internacional por su incorporación al Derecho interno, operando una suerte de novación por medio de la cual el Derecho internacional se transformaría en Derecho nacional, luego de lo cual regiría y se aplicaría en cuanto tal. En el sistema de recepción los tratados se incorporan para la decisión de las causas por vía judicial, a pesar de que ellos pueden no estar vigentes para el Estado que los recepta. En el sistema de adaptación el constituyente nacional incorporaría al texto constitucional una redacción similar a la de los tratados, aunque sin seguirlos en su vigencia internacional. Cada uno de estos tres métodos importaría para Boggiano una forma de nacionalización del Derecho internacional, de modo que lo que en definitiva se aplicaría sería siempre alguna modalidad del Derecho nacional, nunca de manera directa el Derecho internacional. En cambio, en el sistema de referencia la mención al Derecho internacional por parte del Derecho interno respondería a la voluntad de mantener incólume el origen, la vigencia y la interpretación propias del Derecho internacional. Tal sería, a criterio de Boggiano, la situación en nuestro país luego de la reforma constitucional de 1994. Así, sostuvo que:

«En materia de derechos humanos la reforma de 1994 ha seguido una orientación internacionalista a fin de alcanzar la mayor uniformidad posible en las decisiones evitando todo amorío con decisiones de genus loci particularista» (considerando 8, tercer párrafo in fine del caso Arancibia Clavel y considerando 9 in fine del caso Simón).

Esta postura no ha recibido adhesión siquiera mayoritaria de los miembros de la Corte, pero parece ser lo que en doctrina propugnan autores como GiL DOMínguEz.

Como puede apreciarse, las principales diferencias entre las alternativas comentadas se centran, por una parte, en si el Derecho nacional incorpora a las normas internacionales o se limita a declararlas aplicables sin que por ello se estime que pasan a ser parte del Derecho nacional y, por la otra, en si lo que se incorpora o declara aplicable son simplemente las formulaciones normativas internacionales no interpretadas o más bien las normas internacionales en sí mismas, esto es, formulaciones normativas ya dotadas de cierta interpretación.

41 Esta interpretación ha sido propiciada en la doctrina, entre otros, por SCHIFFRIN ( $c f r$. ABREGU y COURTIS, 1997, pp. 115-125) y parece haber sido receptada por la mayoría de la CSJN a partir de los casos Arancibia Clavel y Simón, y reafirmada recientemente en el caso Mazzeo (M.2333.XLII del 13 de julio de 2007). 
Las distinciones conceptuales esbozadas hasta aquí, si bien deberían profundizarse, parecen ofrecer un punto de partida promisorio para efectuar un análisis detallado de modelos complejos de recepción de las normas internacionales en el Derecho interno como el consagrado por la Constitución argentina luego de la reforma de 1994.

\section{REFERENCIAS}

ABReGú, M., y CouRTIS, Ch. (comps.), 1997: La aplicación de los tratados sobre derechos humanos por los tribunales locales, Buenos Aires, Editores del Puerto.

Bulygin, E., 1982: «Time an Validity», en A. MarTino (ed.), Deontic Logic, Computational Linguistics and Legal Information Systems, North Holland-Amsterdam-New York-Oxford, North Holland Publishing Company, pp. 65-82.

— 1990: «An Antinomy in Kelsen's Pure Theory of Law», Ratio Juris, 3, pp. 29-45.

— 1991: «Regla de reconocimiento. ¿Norma de obligación o criterio conceptual? Réplica a J. Ruiz Manero», en Doxa - Cuadernos de Filosofía del Derecho, 9, pp. 311-318.

— 2004: «Is (Part of) Legal Theory Based on a Mistake?», ponencia en el Simposio Internacional de IVR, The Future of Legal Positivism, Alicante.

- 2006: El positivismo jurídico, México, Fontamara.

Caracciolo, R., 1988: El Sistema Jurídico. Problemas actuales, Madrid, Centro de Estudios Constitucionales.

CaStorina de TARQuini, M. ${ }^{a}$ C., 1995: «Supremacía de la Constitución: el nuevo orden», Derecho constitucional de la reforma de 1994, Instituto Argentino de Estudios Constitucionales y Políticos, Buenos Aires, Depalma, pp. 123-174.

Favoreau, L., y Rubio Llorente, F., 1991: El bloque de la constitucionalidad, Madrid, Civitas.

Fuentes TORRIJO, X., 2006: «El Derecho internacional de los derechos humanos y el Derecho interno: definitivamente una pareja dispareja», en www.law.yale.edu/documents/pdf/ SELA/XimenaFuentes spanish pdf.

GARZÓN VALDÉs, E., 1993: «Algunos modelos de validez normativa», en E. GARZÓN VALDÉS, Derecho, Ética y Política, Madrid, Centro de Estudios Constitucionales, pp. 73-105.

Gil Domínguez, A., 1997: En busca de una interpretación constitucional, Buenos Aires, Ediar.

- 2004: «El caso Arancibia Clavel: un fallo fundante en torno a la aplicabilidad», La Ley, 2004D-790, pp. 99-104.

- 2007: La regla de reconocimiento constitucional argentina, Buenos Aires, Ediar.

HART, H. L. A., 1961: El concepto de Derecho, Buenos Aires, Abeledo Perrot, 1963, título original: The Concept of Law, Oxford, Oxford University Press, traducido por G. CARRIó.

— 1983: «Kelsen's Doctrine of the Unity of Law», en H. KIEFER y M. MunITZ (eds.), Ethics and Social Justice, New York, State University of New York, 1968, reimpreso en H. L. A. HART, Essays in Jurisprudence and Pbilosophy, Oxford, Clarendon Press, pp. 309-342.

- 1997: «Postscript» a The Concept of Law, Oxford, Clarendon Press, 1994, pp. 238-276, traducido por M. Holguín en La decisión judicial. El debate Hart-Dworkin, Bogotá, Siglo del Hombre Editores.

Kelsen, H., 1945: General Theory of Law and State, Cambridge, Massachusetts, Harvard University Press.

- 1963: Teoría Pura del Derecho, 2. ${ }^{a}$ ed., México, UNAM, 1979, título original: Reine Rechtslehre, Wien, traducido por R. VERNENGO.

Moreso, J. J., y NAVARRO, P., 1997: «Applicability and Effectiveness of Legal Norms», en Law and Philosophy, 16, pp. 201-219. 
- 1998: «The Reception of Norms and Open Legal Systems», en S. PAUlSON (ed.), Normativity and Norms. Perspectives on Kelsenian Themes, Oxford, Oxford University Press, pp. 273-292.

Navarro, P.; Orunesu, C.; Rodríguez, J. L., y Sucar, G.: «La aplicabilidad de las normas jurídicas», en Analisi e Diritto 2000. Ricerche di Giurisprudenza Analítica, Torino, Giappichelli, pp. 133-152.

- 2004: «Applicability of Legal Norms», Canadian Journal of Law and Jurisprudence, vol. VII, núm. 2, julio, pp. 337-359.

Nino, C. S., 1985: La validez del Derecho, Buenos Aires, Astrea.

RAZ, J., 1979a: «The Identity of Legal Systems», en J. RAz, The Authority of Law, Oxford, Clarendon Press, pp. 78-102.

- 1979b: «Legal Validity», en J. Raz, The Authority of Law, Oxford, Clarendon Press, pp. 146159.

— (2004): «Incorporation by Law», Legal Theory, 10, pp. 1-17.

Requejo Pagés, J. L., 1992: «Consideraciones en torno a la posición de las normas internacionales en el ordenamiento español», Revista Española de Derecho Constitucional, año 12, núm. 34, pp. 41-66.

— 1995a: «Conjunción de sistemas normativos y reordenación del sistema de fuentes», Revista de Estudios Políticos, núm. 90, pp. 113-128.

- 1995b: Sistemas normativos. Constitución y ordenamiento. La constitución como norma sobre la aplicación de normas, Madrid, McGraw-Hill.

- 1998: Las normas preconstitucionales y el mito del poder constituyente, Madrid, Centro de Estudios Políticos y Constitucionales.

RodRíGueZ, J. L., y ViCENTE, D., 1995: «Reflexiones sobre la relación de supremacía constitucional tras la reforma de 1994», Comentarios a la Reforma Constitucional, Buenos Aires, Asociación Argentina de Derecho Constitucional, pp. 257-280.

Ross, A., 1996: «Validity and the Conflict Between Legal Positivism and Natural Law», Revista Jurídica de Buenos Aires, IV, pp. 46-93, reproducido en A. Ross, El concepto de validez y otros ensayos, Buenos Aires, Centro Editor de América Latina, 1969, y México, Fontamara, 1991.

Ruiz MANeRO, J., 1991: «Normas independientes, criterios conceptuales y trucos verbales. Respuesta a Eugenio Bulygin», en Doxa - Cuadernos de Filosofía del Derecho, 9, pp. 281-294.

SAGÜÉs, N. P., 2006a: «Las relaciones entre los tribunales internacionales y los tribunales nacionales en materia de derechos humanos», en N. P. SAGÜÉs, Derecho procesal constitucional. Logros y obstáculos, Buenos Aires, Ad Hoc.

Travieso, J. A., 1999: Garantías fundamentales de los derechos bumanos, Buenos Aires, Hammurabi.

VAnossi, J. R. A., 1976: Teoría constitucional, Buenos Aires, Depalma.

Vanossi, J. R. A., y Dalla Vía, A. R., 2000: Régimen constitucional de los tratados, Buenos Aires, Abeledo-Perrot.

Von Wright, G. H., 1963: Norma y acción. Una investigación lógica, Madrid, Tecnos, 1970, título original: Norm and Action. A Logical Inquiry, London, Routledge \& Kegan Paul. 